\title{
Hubungan lama mengemudi dan tingkat stres pada supir bus antar kota
}

\author{
Juliand Hidayat $^{1}$ Erita Istriana $^{2}$
}

\begin{abstract}
ABSTRAK
\section{LATAR BELAKANG}

Kepadatan penduduk di Indonesia berdampak pada masalah kesehatan, pekerjaan dan transportasi. Salah satu masalah transportasi yang sering dihadapi adalah masalah lalu lintas, ketika jumlah kendaraan tidak sebanding dengan panjang jalanan yang ada, berdampak pula pada lamanya mengemudi yang dapat menyebabkan stres pada pengemudi. Stres tersebut dapat menjadi penyebab terjadinya peningkatan kecelakaan lalu lintas. Data menunjukkan bahwa kelemahan manusia merupakan penyebab utama terjadinya kecelakaan lalu lintas yang menyebabkan korban jiwa. Penelitian ini dilakukan dengan tujuan untuk mengetahui adanya hubungan antara lama mengemudi dan tingkat stres pada supir bus antarkota, untuk dapat mencegah dan menekan angka kecelakaan lalu lintas.

\section{METODE}

Penelitian menggunakan studi observasional dengan pendekatan cross sectional atau potong silang yang mengikutsertakan 113 supir bus antarkota di Terminal Bus Bekasi Timur. Data dikumpulkan dengan cara wawancara menggunakan kuesioner Depression Anxiety Stress Scale 45 (DASS45). Variabel yang diteliti adalah usia, masa kerja, shift kerja, lama mengemudi, pendapatan serta tingkat stres. Analisis data dilakukan secara univariat dan bivariat menggunakan uji Chi-Square dan diolah dengan program SPSS for Windows versi 21.0 dengan tingkat kemaknaan yang digunakan besarnya 0.05 .
\end{abstract}

\section{HASIL}

Sebanyak 68 (60.2\%) subjek yang mengemudi lebih dari 12 jam memiliki tingkat stres berat, sedangkan subjek yang mengemudi kurang dari 12 jam hanya $4(3.5 \%)$ yang memiliki tingkat stres berat. ChiSquare test menunjukkan terdapat hubungan yang bermakna antara lama mengemudi dan tingkat stres pada supir bus antarkota $(p=0.001)$.

\section{KESIMPULAN}

Penelitian ini menunjukkan adanya hubungan antara lama mengemudi dan tingkat stres pada supir bus antarkota.

Kata kunci : lama mengemudi, tingkat stress, usia, masa kerja, shift kerja

\author{
${ }^{1}$ Program Studi Kedokteran, \\ Fakultas Kedokteran, \\ Universitas Trisakti \\ 2 Departemen Ilmu Kesehatan Jiwa, \\ Fakultas Kedokteran, \\ Universitas Trisakti

\section{Korespondensi:} \\ Erita Istriana \\ Departemen Ilmu Kesehatan Jiwa, \\ Fakultas Kedokteran, \\ Universitas Trisakti, Jalan Kyai \\ Tapa No. 260, Grogol, Jakarta Barat \\ Email: erita.istriana@trisakti.ac.id; \\ hey_eta@hotmail.com
}

J Biomedika Kesehat 2019;2(1):34-38 DOI : 10.18051/JBiomedKes.2019. v2.34-38

pISSN: 2621-539X / eISSN: 2621-5470

Artikel akses terbuka (open access) ini didistribusikan di bawah lisensi Creative Commons Attribution 4.0 International (CC-BY 4.0) 
ABSTRACT

\section{Correlation between duration of driving and stress level on inter-city bus drivers}

\section{BACKGROUND}

Population density in Indonesia impact on health, work and transportation problems. One of the most frequent problem in transportation is the flow of traffic, when the number of vehicles are not comparable to the length of the road, impact on long driving that can cause stress on the drivers. That stress also can impact on increasing of traffic accidents. Data shows that human weakness is the main cause of traffic accidents which causes casualities. This study aims to determine the correlation between duration of driving and the stress level on inter-city bus drivers, to be able to prevent and to reduce the number of traffic accidents.

\section{METHODS}

A cross-sectional observational study was conducted and a total of 113 bus drivers in bus station in East Bekasi. Data were collected through interview using Depression Anxiety Stress Scale 45 questionnaire. The variables studied were age, length of service, shift of service, duration of driving, salary, and stress. The data were analyzed in univariate and bivariate using Chi-Square test and processed with SPSS for Windows version 21.0 with a significance level 0.05 .

\section{RESULT}

From $68(60.2 \%)$ subjects who drive more then 12 hours had severe stress level, while those who drive less than 12 hours only $4(3.5 \%)$ subjects had severe stress level. Chi-Square test showed a significant relationship between duration of driving and the stress level on inter-city bus drivers $(\mathrm{p}=0.001)$.

\section{CONCLUSION}

This study showed that there was a significant relationship between duration of driving and stress level in inter-city bus drivers.

Keywords : duration of driving, stress level, age, length of service, shift of service

\section{PENDAHULUAN}

Penduduk Indonesia diproyeksikan mencapai 255.5 juta jiwa pada tahun 2015 . Jumlah penduduk Indonesia diperkirakan akan mencapai 296.4 juta jiwa pada tahun 2030.(1) Dampak kepadatan penduduk yang paling tinggi adalah meningkatnya kebutuhan penduduk akan pendidikan, kesehatan, pekerjaan, termasuk kebutuhan akan transportasi. ${ }^{(2)}$ Bertambahnya jumlah penduduk, maka meningkat pula jumlah kendaraan (bus) dan kebutuhan fasilitas jalan raya sebagai penunjangnya. Salah satu permasalahan lalu lintas pada transportasi darat yang cukup rumit dihadapi saat ini di Indonesia adalah bertambahnya kepemilikan kendaraan, terbatasnya sumber daya untuk pembangunan jalan raya dan belum optimalnya pengoperasian fasilitas arus lalu lintas yang merupakan persoalan utama di banyak negara juga, sehingga sering mengakibatkan terjadinya kemacetan lalu lintas. $(3,4)$

Kondisi fasilitas jalan raya yang tidak sebanding dengan banyaknya kendaraan berdampak pula pada tingkat kepadatan kendaraan di berbagai tempat, yang pada akhirnya dapat menyebabkan kemacetan lalu lintas. Kemacetan juga menambah waktu yang diperlukan oleh seorang pengemudi untuk mencapai suatu jarak tertentu, sehingga juga mempengaruhi lamanya mengemudi. Hal ini juga dapat menyebabkan terjadinya kelelahan, menurunnya konsentrasi, stres, dan disiplin berlalu lintas pengemudi saat mengendarai kendaraannya, dan pada akhirnya dapat menyebabkan terjadinya kecelakaan lalu lintas. ${ }^{(5,6)}$

Lama mengemudi menurut Peraturan Pemerintah No. 44 Tahun 1993 pasal 240 ayat 2 tentang Kendaraan dan Pengemudi adalah 8 (delapan) jam sehari, dan jika lebih akan mempengaruhi tingkat stres pengemudinya. ${ }^{(7,8)}$ Di Indonesia penelitian tentang hubungan antara lamanya mengemudi dan tingkat stres pada supir bus antar kota belum pernah dilakukan, walaupun sudah ada beberapa penelitian yang membahas tentang faktor resiko dan perilaku pengemudi yang dapat meningkatkan terjadinya kecelakaan lalu lintas. Seperti penelitian oleh Aidil $\mathrm{R}^{(9)}$ et al, serta penelitian oleh Farrah $\mathrm{D}^{(10)}$ et al yang mengungkapkan bahwa salah satu penyebab terjadinya resiko kelelahan pada pengemudi adalah lamanya mengemudi. Oleh karenanya penelitian ini perlu dilakukan agar dapat mengurangi jumlah terjadinya kecelakaan lalu lintas dan juga dapat meningkatkan kualitas hidup pengemudi bus antarkota. 


\section{METODE}

Penelitian ini merupakan penelitian analitik observasional dengan menggunakan desain cross sectional, dilaksanakan pada bulan Agustus- Desember 2017. Penelitian dilakukan pada supir bus antarkota yang bekerja di Terminal Bus Bekasi Timur.

Pengambilan sampel penelitian menggunakan cara consecutive non random sampling, dan jumlah sampel adalah 113 orang yang memenuhi kriteria inklusi. Kriteria inklusi penelitian, yaitu supir bus berusia 26-65 tahun dan bersedia menjadi responden dalam penelitian dengan menandatangani informed consent. Kriteria eksklusi yaitu pengemudi yang memiliki riwayat penyakit fisik (hipertensi, jantung, diabetes dan asma bronkial).

Pengumpulan data untuk penelitian ini meliputi data primer yang diperoleh dari populasi secara langsung saat penelitian yaitu melalui penyebaran kuesioner. Instrumen yang digunakan adalah kuesioner Depression Anxiety Stress Scale $^{(11)}$ Setiap subyek penelitian akan diberikan kuesioner sesuai variabel yang ingin diteliti. Data primer kemudian dianalisis secara statistik.

Penelitian ini menggunakan analisis univariat dan bivariat menggunakan metode uji Chi-Square untuk menguji hubungan antara lama mengemudi dan tingkat stres pada supir bus antarkota. Tahapan pengolahan dan analisis data dilakukan dengan program komputer Statistical Pogram for Social Science (SPSS) versi 21.0 for Windows. Protokol penelitian ini telah memperoleh ethical clearance dari Komisi Etik Riset Fakultas Kedokteran Universitas Trisakti dengan nomor 25/KER-FK/VII/2017

\section{HASIL}

\section{Distribusi karateristik responden}

Pada Tabel 1 menyatakan responden terdiri dari 113 supir bus antarkota, yang paling sering didapatkan adalah usia dewasa akhir (37.2\%), pendapatan >Rp. $4.000 .000(46.0 \%)$, lama mengemudi $>12$ jam (85.8\%), dan masa kerja $>5$ tahun (57.6\%). Jumlah responden dengan shift pagi sebanyak 40 responden $(35.4 \%)$, dan mengalami stres berat (63.7\%).
Tabel 1. Distribusi karateristik responden penelitian

$(\mathrm{n}=113)$

\begin{tabular}{lc}
\hline \multicolumn{1}{c}{ Variabel } & $\mathbf{n}(\mathbf{\%})$ \\
\hline Usia & \\
$\quad$ Dewasa awal & $39(34.5)$ \\
Dewasa akhir & $42(37.2)$ \\
Lansia awal & $32(28.3)$ \\
Pendapatan \\
$\quad<$ Rp. 3.600.000 & \\
Sesuai UMR & $12(10.6)$ \\
$\quad>$ Rp. 4.000.000 & $49(43.4)$ \\
Lama mengemudi & $52(46.0)$ \\
$\quad 8-12$ jam & \\
$\quad>12$ jam & $16(14.2)$ \\
Masa kerja & $97(85.8)$ \\
$\quad<1$ tahun & \\
1-5 tahun & $11(9.7)$ \\
$\quad>5$ tahun & $37(32.7)$ \\
Shift kerja & $65(57.6)$ \\
$\quad$ Pagi & \\
$\quad$ Malam & $40(35.4)$ \\
Long shift & $38(33.6)$ \\
Stres & $35(31.0)$ \\
$\quad$ Ringan-sedang & \\
Berat & $41(36.3)$ \\
\hline
\end{tabular}

\section{Hubungan antara lama mengemudi dan masa kerja dan tingkat stres}

Pada Tabel 2 menyatakan dari 72 responden yang memiliki tingkat stres berat, sebagian besar mengemudi $>12$ jam $(60.2 \%)$. Analisis bivariat menunjukkan terdapat hubungan yang bermakna antara lama mengemudi dan tingkat stres $(\mathrm{p}=0.001)$

Sedangkan responden yang telah bekerja menjadi supir bus $>5$ tahun (43.4\%) memiliki tingkat stres berat, analisis bivariat menunjukkan terdapat hubungan yang bermakna antara masa kerja dan tingkat stres $(\mathrm{p}=0.000)$.

\section{PEMBAHASAN}

Hasil penelitian ini menunjukkan rentang usia responden adalah 26 sampai 65 tahun. Dengan hasil rerata usia responden adalah 39.7 tahun, yang termasuk dalam golongan usia dewasa akhir. Sejalan dengan penelitian yang dilakukan oleh Astuti GD terhadap supir bus dengan usia minimal 24 tahun dan usia maksimal 79 tahun didapatkan hasil usia rerata pada penelitiannya berkisar antara 40 tahun. ${ }^{(12)}$ Faktor usia dapat mempengaruhi kemampuan seseorang dalam menghadapi keluhan stress, karena seiring dengan bertambahnya usia akan meningkat kemampuan membuat keputusan, berpikir rasional dan mengendalikan emosinya. Pekerja dengan usia 
Tabel 2. Hubungan antara lama mengemudi, masa kerja dan tingkat stres

\begin{tabular}{|c|c|c|c|}
\hline \multirow[b]{2}{*}{ Variabel } & \multicolumn{2}{|c|}{ Tingkat stres } & \multirow[b]{2}{*}{$\mathbf{p}$} \\
\hline & $\begin{array}{c}\text { Ringan- } \\
\text { Sedang } \\
\text { n (\%) }\end{array}$ & $\begin{array}{l}\text { Berat } \\
\text { n (\%) }\end{array}$ & \\
\hline \multicolumn{4}{|l|}{ Lama mengemudi } \\
\hline 8-12 jam & $12(10.6)$ & $4(3.5)$ & $0.001 *$ \\
\hline$>12 \mathrm{jam}$ & $29(25.7)$ & $68(60.2)$ & \\
\hline \multicolumn{4}{|l|}{ Masa kerja } \\
\hline$<1$ tahun & $11(9.7)$ & $0(0)$ & $0.000 *$ \\
\hline 1-5 tahun & $14(12.4)$ & $23(20.3)$ & \\
\hline$>5$ tahun & $16(14.2)$ & $49(43.4)$ & \\
\hline
\end{tabular}

*uji Chi-Square

yang lebih tua akan mempunyai pengalaman yang tidak dimiliki oleh pekerja dengan usia yang lebih muda, sehingga seorang pengemudi yang lebih tua cenderung mempunyai kondisi kesehatan mental yang lebih baik dibanding pengemudi yang lebih muda. ${ }^{(13)}$

Sebesar $46.0 \%$ responden yang pendapatannya lebih dari UMR yaitu > Rp.4.000.000, cenderung mengemudi lebih dari 12 jam dan diduga hal ini berhubungan juga dengan stres berat. Berbeda dengan penelitian yang dilakukan Astuti GD yang mendapatkan bahwa pengemudi dengan pendapatan tinggi tidak ada yang mengalami tingkat stres berat. ${ }^{(12)}$ Demikian pula teori dari Suma'mur dan penelitian oleh Kompier MAJ, yang menyebutkan bahwa salah satu penyebab stres dalam pekerjaan adalah skala gaji yang rendah, dan pendapatan yang lebih tinggi dapat mengurangi resiko stres kerja, hal ini juga memungkinkan perusahaan untuk merekrut dan mempertahankan pengemudi dengan kualifikasi baik. ${ }^{(13,14)}$

Responden dengan shift kerja $>12 \mathrm{jam}$ $(60.8 \%)$ cenderung memiliki keluhan stres lebih berat dibandingkan responden dengan shift kerja pagi atau malam karena beban kerjanya yang berat. Hal ini sesuai dengan penelitian De Almondes $\mathrm{KM}^{(15)}$ et al Vierdelina $\mathrm{N}^{(16)}$ yang mengungkapkan bahwa kerja shift dapat mempengaruhi kinerja karyawan dalam berbagai cara, contohnya adanya gangguan pada irama tubuh (circadian rhythms), yang dapat menimbulkan kerugian terhadap kemampuan fisik dan mental pekerja shift. Jika pekerja tidak mendapatkan tidur yang cukup maka kinerjanya dapat menjadi buruk. Pada penelitian ini pengemudi yang bekerja secara long shift bekerja lebih dari 12 jam tidak memiliki waktu yang cukup untuk beristirahat. Hal ini berdampak pula terhadap kemampuan fisik dan mentalnya, sehingga keluhan stresnya juga lebih berat dibandingkan pengemudi yang bekerja pada shift biasa (shift pagi atau shift malam saja), yang cenderung masih memiliki waktu istirahat yang cukup dibandingkan dengan pengemudi yang bekerja long shift. ${ }^{(17)}$

Pada penelitian ini $43.4 \%$ responden dengan masa kerja $>5$ tahun cenderung memiliki keluhan stres berat dibandingkan responden dengan masa kerja $<5$ tahun. Sesuai dengan penelitian oleh Nahar $\mathrm{BN}$, yang menyebutkan bahwa rata-rata masa kerja responden penelitiannya ( 9 tahun) berisiko memiliki

keluhan stres dibandingkan dengan supir yang memiliki masa kerja $<5$ tahun. ${ }^{(18)}$ Masa kerja yang lama mempengaruhi pengemudi dalam melaksanakan pekerjaannya karena adanya rutinitas dalam bekerja sehingga dapat menyebabkan kejenuhan dan beban kerja yang akhirnya dapat menyebabkan stres. ${ }^{(18,19)}$

Penelitian ini memiliki keterbatasan yang mungkin ikut mempengaruhi hasil penelitian yang ada, antara lain pengisian kuesioner penelitian dilakukan saat responden bekerja (di terminal bus), dan disertai dengan pengukuran indikator stres kerja yang cukup banyak. Selain itu variabel yang digunakan dalam penelitian ini hanya menghubungkan faktor risiko yang diperkirakan memiliki hubungan dengan variabel stres kerja, sehingga masih terdapat kemungkinan variabel-variabel lain yang belum masuk dalam penelitian.

\section{KESIMPULAN}

Lama mengemudi berhubungan dengan tingkat stres pada supir bus antarkota, oleh karenanya perlu dilakukan promosi kesehatan, 
dan edukasi, sehingga dapat mencegah atau menurunkan tingkat stres pada pengemudi bus antarkota. Perusahaan pengelola bus antarkota juga disarankan untuk mematuhi peraturan jam kerja bagi para pengemudinya dan tidak memaksa mereka untuk bekerja diluar batas yang sudah ditetapkan, sehingga dapat meningkatkan kualitas hidup pengemudi bus antar kota dan mengurangi kemungkinan terjadinya kecelakaan lalu lintas antar kota.

Perlunya penelitian lanjutan untuk mengetahui faktor-faktor lain yang menyebabkan tingkat stres pada supir bus antarkota, seperti: tingkat kemacetan, kualitaskendaraan, penumpang yang bermasalah dan pemeriksaan kesehatan berkala, serta sebaiknya dilakukan saat responden beristirahat, agar responden lebih nyaman saat mengisi kuesioner dan hasil penelitian yang didapatkan akan lebih baik.

\section{DAFTAR REFERENSI}

1. Badan Perencanaan Pembangunan Nasional. Proyeksi Penduduk Indonesia 2010-2035, $1^{\text {st }}$ ed. Jakarta:Badan Pusat Statistik, 2013.

2. Christiani C, Tedjo P, Martono B. Analisis Dampak Kepadatan Penduduk Terhadap Kualitas Hidup Masyarakat Provinsi Jawa Tengah. Serat ActiyaJurnal Ilmiah, UNTAG Semarang; 2013.

3. Engelfriet L. The Impact of Urban Density on Car Dependency and Related Energy Consumption, paper research project. Vrije Universiteit Amsterdam, The Netherlands;2015.http://spinlab. vu.nl/wp-content/uploads/2016/09/Research_ Project Lara Engelfriet.pdf

4. Abubakarar, Iskandar. Menuju Lalu Lintas dan Angkutan Jalan yang Tertib. Jakarta : Direktorat Jenderal Perhubungan Darat; 1995.

5. Melisa, Nani, Novita, Zuraida R. Analisis beban kerja yang mempengaruhi tingkat kelelahan pengemudi kendaraan roda empat rute JakartaBandung. Industrial Engineering, Universitas Bina Nusantara Jakarta; 2013.

6. Joshi AR, Vaidya SM. Evaluation of perceived stress in bus drivers of Pune city. National Journal of Physiology, Pharmacy and Pharmacology 2017;7(1):90-3.

7. Peraturan Pemerintah No.44 Tahun 1993 Pasal 240 dan 241 tentang Kendaraan dan Pengemudi dalam: Undang-Undang Lalu Lintas dan Angkutan Jalan; 1993.

8. Undang-Undang No 22 tahun 2009. Tentang Lalu Lintas dan Angkutan Jalan. Yogyakarta: Pustaka Yustisia; 2009

9. Rahman A, Hermana B. Faktor-faktor yang Mempengaruhi Kelelahan Pengendara Mobil Pribadi. Universitas Gunadarma; 2007.

10. Damopoli FC, Kawatu PAT, Tumbol RA. Faktor-faktor yang Berhubungan dengan Kelelahan Kerja Pada Supir Bis Trayek Manado-Amurang di Terminal Malalayang Manado. FKM Universitas Sam Ratulangi
Manado; 2013.

11. Lovibond SH, Lovibond PF. Manual for the depression anxiety stress scale. $2^{\text {nd }}$ ed. Sydney: Psychology Foundation of Australia;1995.

12. Astuti GD. Faktor-faktor yang Berhubungan dengan Kejadian Stres Kerja pada Pengemudi Taksi New Atlas Semarang Tahun 2015. Ilmu Kesehatan Masyarakat, Universitas Negeri Semarang; 2015.

13. Kompier MAJ. Bus Driver: Occupational Stress and Stress Prevention, Working Paper. Department of Work and Organizational Psychology. Geneva: University of Nijmegen, ILO; 1996

14. Suma'mur PK. Higiene Perusahaan dan Kesehatan Kerja. 13th ed. Jakarta: Gunung Agung; 1996.

15. de Almondes KM, Araujo JF. The Impact of Different Shift Work Schedule on The Levels of Anxiety And Stress in Workers in Petrochemichals Company. Estudos de Psicologia 2009; 26(1): $15-$ 23. DOI:10.1590/S0103-166X2009000100002

16. Vierdelina N. Gambaran Stres Kerja dan Faktorfaktor yang Berhubungan pada Pengemudi Bus Patas 9B Jurusan Bekasi Barat-Cililitan/ Kampung Rambutan, tahun 2008 . Universitas Indonesia Jakarta; 2008.

17. Fitri AM. Analisis Faktor-Faktor yang Berhubungan Dengan Kejadian Stres Kerja Pada Karyawan Bank (Studi pada karyawan Bank BMT). Jurnal Kesehatan Masyarakat 2013; 2(1).

18. Nahar BN, Ahsan GU, Khan NA. Prevalence of $10 \mathrm{w}$ back pain and Associated Risk Factors Among Professional Car Drivers in Dhaka City, Bangladesh. South East Asia J of Public Health 2012; 2(1):60-3.

19. Useche SA, Alonso F, Cendales BE. Autukevičiūtè R, Serge A. Burnout, Job Strain and Road Accidents in The Field of Public Transportation: The Case of City Bus Drivers. Journal of Environmental and Occupational Science 2017; 6(1): 1-7. DOI: $10.5455 /$ jeos. 20170202074636 